\title{
«Corazón de piedra»: escultura y poesía en el madrigal «Retrato de Lisi en mármol» de Quevedo*
}

\author{
Adrián J. SÁEZ \\ Università Ca' Foscari di Venezia
}

\begin{abstract}
Dentro del corpus escultórico-poético de Quevedo, el "Retrato de Lisi en mármol" es un ejemplo excelente de la estrategia de composición y reescritura de modelos de Quevedo: de hecho, el poema es una nueva versión de un texto de Groto, y cuenta con dos versiones, que muestran la progresiva intensificación en el uso de ideas artísticas.
\end{abstract}

Keywords: Quevedo, Groto, intertextualidad, arte, escultura.

Hay detalles que valen su peso en oro, por baladíes que pueden antojarse en un primer vistazo. Así parece ser el caso del inicio de El Parnaso español (Madrid, Díaz de la Carrera, I648) de Quevedo, que se abre con tres sonetos fuertemente hermanados: dos «A la estatua de bronce del santo rey don Filipo III» (núms. 2II y 2I2) y otro más dedicado a un monumento de Carlos $\mathrm{V}$ («Las selvas hizo navegar y el viento», núm. 2I4). Estos tres poemas morales, que casi forman un tríptico perfecto de reyes quevedianos que enlazan con cuestiones morales y políticas, dan fe de la presencia de la escultura en la poesía de Quevedo (Garzelli 2008: I55-I62; Sáez 2017c).

$\mathrm{Y}$ es que, aunque la pintura gana de lejos al resto de las artes en la obra poética quevediana, dentro del intenso y provechoso gusto artístico de Quevedo hay espacio igualmente para el dibujo caligráfico (el soneto «Al retrato del rey nuestro señor hecho de rasgos y lazos, con pluma, por Pedro [Díaz] Morante», núm. 220) (Garzelli I993), la tapicería (el romance «Matraca de los paños y sedas», núm. 763) (Sáez 2015f) y hasta la escultura, como se pretende mostrar a partir de un botón de muestra que puede dar mucho juegor.

\footnotetext{
* Este trabajo se enmarca en los proyectos SILEM: Sujeto e institución literaria en la Edad Moderna (referencia FFI20I4-54367-C2-I-R del Ministeriode Economía y Competitividad, Gobierno de España) coordinado por Pedro Ruiz Pérez (Universidad de Córdoba) y VIES: Vida y escritura I: Biografía y autobiografía en la Edad Moderna (FFI2015-6350I-P) capitaneado por Luis Gómez Canseco y Valentín Núñez Rivera (Universidad de Huelva). Como siempre, se agradecen los sabrosos comentarios de mis queridos colegas Fernando Plata (Colgate University), Jesús Ponce Cárdenas (Universidad Complutense de Madrid) y Antonio Sánchez Jiménez (Université de Neuchâtel).

I Sobre el Quevedo pictórico, ver especialmente Garzelli (2008), Cacho Casal (20I2: 89-I27) y Sáez (2015a, 2015b, 2015c, 2015d, 2015e, 2017b y en prensa). Se podrían considerar otras menciones estatuarias y otros poemas escultóricos, que se examinan en Nider (2017) y Sáez (2017a
} 


\section{Poema para una mujer de piedra}

Se trata del madrigal «Retrato de Lisi en mármol» (núm. 507), del que se conservan dos versiones².

I

BNE, signatura: Mss/3796

Un famoso pintor, Lisarda esquiva, te ha retratado en una peña viva, y ha puesto más cuidado en retratarte que la Naturaleza en engendrarte; pues si te dio blancura y pecho helado, él mismo te lo ha dado:

bellísima en el mundo te hizo ella y él no te ha retratado menos bella. Mas ella, que te tuvo por piadosa, de hueso te compuso y carne hermosa, y él, que vuelta te mira en piedra

de lo que tú te has hecho te retrata.

\section{[ingrata,}

De entrada, hay un pequeño detalle de interés: en la primera redacción del poema se establece un juego picto-poético ( $U$ Un famoso pintor, Lisarda esquiva», v. I) que cede paso a la escultura únicamente en un segundo momento, en una innovación muy significativa marcada desde el incipit ${ }^{3}$. Alguna vez se ha pensado que el madrigal en cuestión era una suerte de epitafio dedicado a la muerte de doña Luisa de la Cerda, supuesta amada de Quevedo que se ocultaría tras la máscara de «Lisis» (Gómez de la Serna I950: 6), pero es idea ya descartada de la baraja crítica que nada importa en esta ocasión ${ }^{4}$.

Ni falta que hace, porque el poema quevediano ya cuenta con dos buenas cartas de valor: su fundamento intertextual italiano y el juego escultó-

y 20I7c).

2 Se cita siempre por las ediciones consignadas en la bibliografía, con ocasionales modificaciones de puntuación. La numeración procede de la edición de Blecua (I969-197I).

3 La variante del nombre no importa gran cosa, ciertamente, pero las modificaciones de la reescritura van más allá de «cambios coyunturales» (Fernández Mosquera 1999:358), tal como muestra la variación de artes. Con toda lógica, el apóstrofe más frecuente en el cancionero es el nombre de Lisi y sus variantes (1999: 236 y 30I-302).

4 Al hilo de otras ideas, Walters (1984: 65-66) ya niega la condición post mortem del poema. 
rico-poético que va de la mano. Efectivamente, el cañamazo principal del poemita procede de la influencia de Groto, porque, si bien es verdad que guarda relación con otros poemas de Quevedo del ciclo dedicado a Lisi («Retrato no vulgar de Lisi», «Retrato de Lisi que traía en una sortija», núms. I05 y 127) (Schwartz y Arellano 1998: 265), el modelo directo del poema es un madrigal grotesco («Cignata di crudeltà alla sua donna», Rime (parte prima), núm. IOI) (Fucilla I960: 205-206)5:
Un nobile scoltore ha di te fatto in viva pietra un natural ritratto; anzi, ha posto in ritrarti più senno che Natura in generarti: ella ti diede il bianco, te 'l diè lo scoltor anco; bellissima nel mondo ti fec'ella, non men ti fece ei bella. Ma perché ti stimò pietosa e molle, ella ti fe' di carne e di midolle. Ma lo scoltor vie più saggio di lei, ti fe' di sasso, apunto come sei.

El gusto quevedesco por Groto cuenta al menos con dos buenas razones: de modo general, se relaciona con la afinidad que presenta con otros ingenios de la corriente antipetrarchesca que retuercen con sorna la galería de topoi poéticos (Cacho Casal 2003), a la par que seguramente durante la etapa italiana de Quevedo (I6I3-I6I9, a caballo entre Sicilia y Nápoles) todavía mantenía toda su fuerza la fama de la poesía de Groto, que había visto la luz poco antes en una cuidada edición completa (I6IO, con sucesivas reediciones) ${ }^{6}$. Así, afinidad de esprit y contexto favorecen este lazo intertextual.

Por de pronto, en el careo entre ambas poesías se aprecia una pequeña variación formal: si bien Quevedo sigue el patrón del madrigal, una forma italiana por definición, lleva a cabo una pequeña amplificatio (de I2 a I4 vv.) que asimila el esquema inicial al molde del soneto (Cuevas 2002: 75), que era desde siempre el cauce predilecto tanto para las composiciones ecfrásticas como para los alardes de ingenio ${ }^{7}$.

5 Esta primera entrega cuenta con una aparición individual (Venezia, Zopini, 1577) y la edición completa (Venezia, Ambrosio Dei, I6Io), ya póstuma. Ver los acercamientos generales de Fucilla (1960: 195-209), Sbriziolo (2013) y Ceribelli (2017). Andrés Sánchez-Lafuente y Beltrán Noguer (2005: 249) proponen un eco de Propercio sobre la crueldad y la blancura de la amada desdeñosa, que más bien parece un topos bien conocido.

6 Según Rey y Alonso Veloso (20II: XVI), Quevedo apreciaba a Groto por sus características burlas en poemas amorosos. Ver el repaso italiano de Cappelli (2017).

7 Alonso Veloso (2012b: 635) aprecia que en este proceso de reescritura se produce asimismo un cambio de rima, justo en el lugar donde se introducen los dos nuevos versos. A su vez, 
Hay otra serie de variaciones significativas, pero conviene empezar por el principio con el baile de artes de la escultura a la pintura y de nuevo vuelta la escultura. Normalmente se entiende que la primera redacción del poema quevediano es más cercana y fiel al modelo italiano (Cuevas 2002: 78-79; Alonso Veloso 20I2b: 635), pero en verdad la recuperación del arte escultórica parece compensar -todo lo parcialmente que se quiera- la desviación quevediana ${ }^{8}$. Se puede buscar alguna razón para esta doble reescritura: la apuesta inicial por la pintura probablemente tenga que ver tanto con el triunfo del ars pictorica dentro del clásico paragone con la escultura como con la búsqueda de coherencia con el resto de voces artísticas (en la órbita del «retrato» ya anunciado desde el título en la versión final), pero luego en un segundo momento se vuelve a la escultura seguramente como un envite de originalidad tanto en el cancionero dedicado a Lisi como en el panorama general de la poesía artística, por mucho que a la vez suponga otra muestra de apego al modelo hipotextual ${ }^{9}$.

Si con el primer envite se lograba un poema acaso más tradicional dentro de la galería de poemas retratísticos, con esta segunda jugada se consigue un diseño más elaborado, al tiempo que se aprovecha mejor la potencia del esquema «grotesco» para el concepto artístico y da nuevo vigor a la crítica de la actitud desdeñosa de la amada, que casa mucho mejor con una estatua que con una pintura.

De hecho, la revisión de Quevedo es una verdadera reescritura artística, pues desarrolla en dos tiempos tanto una mayor originalidad como un acento más fuerte en conceptos e ideas sobre el arte. Para mostrarlo, comento seguidamente una serie de variaciones significativas entre el modelo de Groto y las dos versiones quevedianas ${ }^{\mathrm{IO}}$.

Si el arranque escultórico supone una vuelta a los orígenes con cambio en el apóstrofe a la amada de regalo, destaca un proceso de pulido estilístico por el que Quevedo evita las repeticiones de «retratar» y derivados: es claro que resulta excesiva la presencia en la primera redacción de tantas voces de la misma familia léxica («te ha retratado en una peña viva», v. 2 ; «y ha puesto más cuidado en retratarte», v. 3; «y él no te ha retratado menos bella», v. 8; "de lo que tú te has hecho te retrata», v. I2), de las que apenas salva dos apariciones (idéntico el v. 3 y el último como «de lo que tú te hiciste te retrata»,

Ponce Cárdenas (2012) precisa que en la transferencia de este juego picto-poético, los ingenios españoles tienden a decantarse por la octava real.

8 De hecho, en la galería de modelos que habitualmente se le sacan al poema (Petrarca, Marino y compañía) (Schwartz y Arellano 1998: 856-858; Rey y Alonso Veloso 2013: 19I-193) la escultura brilla por su ausencia.

9 Con todo, los títulos son algo sospechosos, porque proceden en muchos casos de González de Salas, editor del volumen (Alonso Veloso 2012a).

Io Un ejercicio parecido, pero de carácter descriptivo, se encuentra en Alonso Veloso (20I2b: 635-636), mientras Ceribelli (2017) ofrece otros detalles más jugosos. 
v. I4), que hacen juego con el epígrafe («Retrato en mármol»). Esta reescritura es de todo menos inocente, porque Quevedo aprovecha para añadir dos nuevas cuestiones de teoría artística: con el primer cambio («en una piedra te ha imitado viva», v. 2) entra en escena la imitatio (o mímesis), fundamento de la creación artística desde Aristóteles por el que se entiende el arte como imitación de la naturaleza; a su vez, con el segundo ("y él no te ha repetido menos bella», v. 8) se insiste en la perfección de la escultura, que es fiel al modelo real.

Todavía más interesante es otra pequeña variación que tiene que ver, de paso, con la fidelidad al modelo intertextual: en la primera versión, Quevedo sigue a Groto en la metáfora generativa («più senno che Natura in generarti» / «que la Naturaleza en engendrarte», v. 4), de producción ex nihilo, pero durante la revisión posterior se decanta por un tecnicismo pictórico («que la Naturaleza en figurarte», v. 4). Y es que la voz «figurar» se emplea preferentemente para representar la acción de pintar o el retrato mismo desde los sonetos pictóricos de Aretino (Ponce Cárdenas 2012: 9I) ${ }^{\mathrm{II}}$. De este modo, la Naturaleza gana una cierta dimensión artística (Natura artifex) con la que compite y a la que vence el escultor del poema con su obra.

Luego de una pareja de versos calcados casi a la letra del espejo grotesco (vv. 8-9) con paranomasia en forma de reduplicatio incluida («bella» / «ella»), viene la mayor desviación de la reescritura quevediana, con un verso de la primera versión («de hueso te compuso y carne hermosa», v. Io) que deja paso a tres en la segunda («de materia tan blanda y tan suave / te labró, que no sabe / del jazmín distinguirte y de la rosa», vv. IO-I2), con un pequeño retoque anterior («te tuvo por piadosa» pasa a ser «te quiso hacer piadosa», v. 9). Con esta adición, que rompe con el esquema métrico inicial (ver supra), Quevedo refuerza grandemente el contraste entre las naturales cualidades positivas de la mujer (con la blandura al frente), que se muestra explícita en la primera redacción y más elaborada poéticamente en la segunda (con las imágenes florales), frente a la dureza de la piedra de la escultura (en vv. II-I2 y VV. I3-I4 de cada una), que tan bien conviene en realidad a su carácter desdeñoso ${ }^{12}$.

Tal vez otro cambio mínimo tenga algo de importancia, porque una pequeña modificación sintáctica (de «él mismo te lo ha dado» a «él lo mismo te ha dado», v. 6) parece insistir tanto en la coherencia entre la amada y la

II Algunas notas sobre la influencia poética de Aretino en Sáez (2015a). Cuevas (2002: 80-8I) ya entendía el valor artístico del término.

I2 Alonso Veloso (20I2b: 636) ya anota este alejamiento deliberado del modelo con valor contrastivo. Fernández Mosquera (I999: I07-I08) explica que la identificación entre la amada y la piedra no es frecuente en Canta sola a Lisi, si bien pueden encontrarse otros casos en Quevedo (núms. 354 y 367 ) y recuerda otros «mármoles» quevedianos. Sobre las metáforas vegetales en el ciclo a Lisi, ver Fernández Mosquera (1999: 92-I03). 
escultura, como en la fidelidad del escultor al verdadero ethos del modelo, que logra reproducir (imitar) en piedra el pétreo carácter de Lisis, tal como se muestra en el final con paradoja conclusiva.

Cuevas (2002: 82-85) tiene razón cuando aprecia la mixtura de alabanza y vituperio de la dama, pero no es preciso acudir a ningunos «granos de filosofía y teología» sobre la polémica en torno al libre albedrío para explicar la actitud cruel de la dama y su perfecta correspondencia con el mármol. En compensación, se encuentra la celebración del ingenio del artista, que logra una perfecta correspondencia con su modelo, frente a otros casos en los que se discute sobre la dificultad de reflejar artísticamente la belleza de la dama (valga el soneto «Si quien ha de pintaros, ha de veros», núm. 307) (Sáez, en prensa).

Se puede añadir un detalle más acerca del artista: en el madrigal de Groto el elogio del «scoltore», que aparece mencionado por tres veces (vv. I, 6 y II), se cierra al final con un encomio de su sabiduría y buen hacer frente a la amada («vie più saggio di lei», v. II), mientras que en los dos poemas quevedianos se relega al artista a un segundo lugar, pues apenas se recuerda en una ocasión (v. I) y basta. En este sentido, Quevedo sigue la tendencia habitual de su poesía artística al elogio de un escultor anónimo, cual si fuera representante par excellence de su arte (ver los sonetos núms. 2II-2I2, 2I4, por recordar solo los textos «escultóricos»), mientras que solo cuenta con dos ejemplos de epigramas retratísticos donde ensalza a los artistas con nombres y apellidos (Guido Reni y Pedro Morate, núms. 215 y 220), como si fueran «i veri protagonisti della poesia» (Garzelli 2008: 162) ${ }^{13}$.

\section{Amores imposibles: el desdén y la estatua}

Todavía lejos de la máxima de «l'art pour l'art», los madrigales de Groto y Quevedo dan una vuelta de tuerca a la tradición de la belle dame sans merci y conectan -algo de refilón- con el tema del amor a las estatuas. Y es que, como dice González García (2006), la agalmatofilia supone una atracción sexual (parafilia) por las esculturas y el reconocimiento de la maestría del artista capaz de dotar de vida a una figura esculpida que se encuentra en un buen manojo de relatos desde la Antigüedad: tal como se presenta en este estupendo trabajo, estas historietas podían poseer varios significados, desde tener un fin moralizante y valer para criticar la idolatría y otras prácticas paganas, hasta ser un argumento mayor para justificar la idea del artista

I3 Sobre este esquema epigramático a caballo entre Italia y España, ver Ponce Cárdenas (2012, 2013a y 2013b). 
como deus artifex y defender la excelencia de la escultura en el paragone con la pintura.

En este sentido, en este madrigal quevediano y otros poemas amoroso-escultóricos la cosa no va tan lejos (hasta la macula libidinis), pero sí se da un salto de la estatua-amada a la amada-estatua que tiene su interés, porque - entre otras cosas- el amante queda delineado casi cual nuevo Pigmalión ${ }^{14}$. En ambos casos el fin es el mismo: el tormento por la falta de correspondencia amorosa, que -si cabe- puede ser más grave en el caso de los amantes rechazados porque la imposibilidad de un amor feliz no procede de las condiciones naturales (una figura inerte) sino del desdén de la dama en cuestión. Por ello, mutatis mutandis se puede conectar con otro soneto de Quevedo dedicado a la crueldad de la dama (núm. 354), en el que el poeta recuerda el mito de Anajárete para criticar «la dureza extraña» de la mujer, que le valió ser convertida «en piedra» (vv. 6-7) por haber rechazado el amor del pastor Ifis, de la misma manera que la dama del poema se muestra dura como hija de «algún monte» (v. I3).

Asimismo, la preferencia por la escultura del poema durante la reescritura quevediana vuelve a la disputa entre las artes, puesto que solo la imagen esculpida puede dar buen testimonio de la frialdad y dureza de la amada. De ser así, se confirma el buen tino de Quevedo en materia artística, pues con este madrigal y especialmente con los cambios reescriturales demuestra estar al tanto de las cuestiones que marcaban el arte de su tiempo.

\section{Toque final}

En pocas palabras, la presencia de la escultura en la poesía de Quevedo es mucho más que un juego que redondea la paleta artística del poeta, pues en un madrigal de filiación italiana logra dar forma a varias ideas centrales del arte coetáneo a partir de un agudo ejercicio de reescritura que demuestra -entre otras cosas- el proceso de evolución de la poética quevediana. Desde un primer ejercicio de imitatio más centrado en la fidelidad al modelo grotesco se pasa a un poema con sabor propio con el que Quevedo reflexiona sobre el arte de la escultura y ciertos topoi poéticos. Y es que, a fin de cuentas, escribir sobre arte es todo un arte.

I4 Acerca de este mito en la poesía española (pero no en Quevedo), ver Cristóbal (I993). 


\section{Bibliografía}

Alonso Veloso, María José, «Antecedentes de los epígrafes de la poesía de Quevedo en la literatura clásica y del Siglo de Oro. Con una hipótesis sobre su autoría», Revista de Literatura, 74.I47, 2012a, pp. 93-138.

—. «Los madrigales de Quevedo», Bulletin Hispanique, II4.2, 2012, pp. 62I-644. Cacho Casal, Rodrigo, La poesía burlesca de Quevedo y sus modelos italianos, Santiago de Compostela, Universidade de Santiago de Compostela, 2003.

- La esfera del ingenio: las silvas de Quevedo y la tradición europea, Madrid, Biblioteca Nueva, 2012.

Cappelli, Federica, «Hacia una definición del papel de Quevedo en Italia», La Perinola, 2I, 2017, pp. 17-40.

Ceribelli, Alessandra, «La influencia de Luigi Groto en la poesía amorosa de Quevedo», en Serenísima palabra: Actas del X Congreso de la AISO (Venecia, I4-I8 de julio de 20I4), eds. F. del Barrio, A. Zinato, A. Bognolo, D. Pini y V. Ojeda Calvo, Venezia, Biblioteca di Rassegna Iberistica, 20I7, pp. 203-210.

Cristóbal, Vicente, «Pigmalión y la estatua: muestras de un tema ovidiano en la poesía española», Cuadernos de Filología Clásica, 23.I, 2003, pp. 6387.

Cuevas, Cristóbal, «Retrato de Lisi en mármol», La Perinola, 6, 2002, pp. 7387.

Fernández Mosquera, Santiago, La poesía amorosa de Quevedo: disposición y estilo desde «Canta sola a Lisi», Madrid, Gredos, 1999.

Fucilla, Joseph G., Estudios sobre el petrarquismo en España, Madrid, CSIC, 1960.

Garzelli, Beatrice, «"Bien con argucia rara y generosa”: Pedro Morante visto da Quevedo», Rivista di Filologia e Letterature Ispaniche, I, I998, pp. I43I56.

—. «Nulla dies sine linea»: letteratura e iconografia in Quevedo. Pisa, ETS, 2008.

Gómez de la Serna, Ramón, "Quevedo y las mujeres», Clavileño, I, I950, pp. 63-68.

González García, Juan Luis, «Por amor al arte: notas sobre la agalmatofilia y la imitatio creatoris, de Platón a Winckelmann», Anales de Historia del Arte, 16, 2006, pp. I3I-I50.

Groto, Luigi, Le rime di Luigi Groto, cieco d'Adria, ed. B. Spaggiari, Adria, Apogeo, 2014 .

Nider, Valentina, "Los clásicos desde el Siglo de Oro: de estatuas y cortesanas en los sonetos de Quevedo sobre Friné (Polimnia 78 y 79)", Criticón, I3I, 20I7, pp. 89-IO6. 
Ponce Cárdenas, Jesús, «La octava real y el arte del retrato en el Renacimiento», en Poesía y pintura en el Siglo de Oro, ed. J. Ponce Cárdenas, Criticón, II4, 2OI2, pp. 7I-IOO.

—. “Cebado los ojos de pintura”: epigrama y retrato en el ciclo ayamontino», en Góngora y el epigrama: estudios sobre las décimas, eds. J. Matas Caballero, J. M. a Micó y J. Ponce Cárdenas, Madrid / Frankfurt, Iberoamericana / Vervuert, 20I3a, pp.I43-I66.

- «Sociabilidad cortesana y elogio artístico: epigramas al retrato en la poesía de Góngora», en Sociabilidad y literatura en el Siglo de Oro, ed. M. Albert, Madrid / Frankfurt, Iberoamericana / Vervuert, 2013b, pp. I4I-I63.

Quevedo, Francisco de, «Un Heráclito cristiano», "Canta sola a Lisi» y otros poemas, eds. L. Schwartz e I. Arellano, Barcelona, Crítica, I998.

—. Obra poética, ed. J. M. Blecua, Madrid, Castalia, I969-I97I, 4 vols.

Rey, Alfonso \& María José Alonso Veloso (eds.), F. de Quevedo, Poesía amorosa ("Erato», sección primera), Pamplona, Eunsa, $201 \mathrm{I}$.

-. F. de Quevedo, Poesía amorosa: "Canta sola a Lisi» («Erato», sección segunda), Pamplona, Eunsa, 2013.

Sáez, Adrián J., "Aretino y Quevedo: perfiles de la poesía pictórica», Calíope: Journal of the Society for Renaissance and Baroque Poetry, 20.2, 2015a, pp. II9-I49.

-. El ingenio del arte: la pintura en la poesía de Quevedo, Madrid, Visor Libros, 20I5b.

—. «Entre el pincel y la pluma: boceto sobre la poesía de Quevedo y la pintura», en El duque de Medina Sidonia: mecenazgo y renovación estética, eds. J. M. Rico García y P. Ruiz Pérez, Huelva, Universidad de Huelva, 20I5c, pp. 38I-398.

—. «"Las aves del imperio coronadas”: poesía y arte en el túmulo de Quevedo a sor Margarita de Austria», Artifara, 15, 2015d, pp. 213-222. [En red.]

-. «Quevedo y Armenini: lecturas pictóricas de un poeta», Janus: Estudios sobre el Siglo de Oro, 4, 20I5e, pp. I-24. [En red.]

-. "Quevedo y el arte de la tapicería: el romance "Matraca de los paños y sedas"», Boletín de la Real Academia Española, 95.3I2, 20I5f, pp. 453-470.

—. «Las estatuas de Quevedo: arte y encomio funeral en un poema al duque de Osuna», en La estirpe de Pigmalión: poesía y escultura en el Siglo de Oro, eds. M. Rubio Árquez y A. J. Sáez, Madrid, SIAL, 20I7a, pp. 217-23I.

- «El perdón de la Magdalena: erotismo y pintura en un soneto de Quevedo», en "En la concha de Venus amarrado»: erotismo y literatura en el Siglo de Oro, ed. P. Marín Cepeda, Madrid, Visor Libros, 20I7b, pp. IO7I2O.

—. «Reyes de bronce: tres poemas escultóricos de Quevedo», Janus: Estudios sobre el Siglo de Oro, 6, 20I7c, pp. 2II-229. [En red.] 
-. "Quevedo and the Mirror: Poetry, Painting and the Problem of Beauty», en The Dialectics of Faith and Doubt in Seventeenth-Century Spain: Visual and Literary Reflections, eds. M. Ancell y A. Georgievska-Shine, Toronto, Toronto University Press, en prensa.

Sánchez-Lafuente Andrés, Ángela \& Teresa Beltrán Noguer, «Quevedo: dos poetas del amor», Myrtia, 20, 2005, pp. 243-254. [En red.]

Sbriziolo, Carola, «La presencia de Groto en la poesía de Quevedo: tres poemas de argumento mitológico", Acta literaria, 47, 2013, pp. II7-I33.

Walters, D. Gareth, «Una nueva ordenación de los poemas a Lisi de Quevedo», Criticón, 27, 1984, pp. 55-70. 